\title{
A Japan nationwide web-based survey of patient preference for renal denervation for hypertension treatment
}

\author{
Kazuomi Kario $^{1} \cdot$ Hideaki Kagitani $^{2} \cdot$ Shoko Hayashi $^{2} \cdot$ Satsuki Hanamura ${ }^{2} \cdot K^{2}$ eisuke Ozawa ${ }^{2} \cdot$ Hiroshi Kanegae $^{1}$
}

Received: 27 August 2021 / Revised: 7 September 2021 / Accepted: 9 September 2021 / Published online: 17 October 2021

(c) The Author(s) 2021. This article is published with open access

\begin{abstract}
Renal denervation is a potential alternative to antihypertensive drug therapy. However, data on patient preference for this treatment option are limited and there are no data specifically from Asian patients. This study evaluated patient preference for renal denervation in patients with hypertension from Japan. Patients were a subset of those who participated in a March 2020 online electronic survey of patients with hypertension who had regularly visited medical institutions for treatment, were receiving antihypertensive drug therapy and had home blood pressure recordings available. The survey included a question about patient preference for treatment with renal denervation. A total of 2,392 patients were included (66\% male, mean age $59.8 \pm 11.6$ years, mean duration of hypertension $11.4 \pm 9.5$ years). Preference for renal denervation was expressed by 755 patients $(31.6 \%)$, and was higher in males than in females, in younger compared with older patients, in those with higher versus lower blood pressure, in patients who were less adherent versus more adherent to antihypertensive drug therapy, and in those who did rather than did not have antihypertensive drug-related side effects. Significant predictors of preference for renal denervation on logistic regression analysis were younger patient age, male sex, higher home or office systolic blood pressure, poor antihypertensive drug adherence, the presence of heart failure, and the presence of side effects during treatment with antihypertensive drugs. Overall, a relevant proportion of Japanese patients with hypertension expressed a preference for renal denervation. This should be taken into account when making shared decisions about antihypertensive drug therapy.
\end{abstract}

Keywords Hypertension $\cdot$ Patient preference $\cdot$ Renal denervation $\cdot$ Blood pressure

\section{Introduction}

An estimated 1.13 billion people worldwide have hypertension [1]. Despite a growing number of therapeutic options for hypertension, less than $20 \%$ of patients globally who are being treated for high blood pressure (BP) achieve BP control [1], something that has been described as the "hypertension paradox" [2].

Supplementary information The online version contains supplementary material available at https://doi.org/10.1038/s41440021-00760-9.

Kazuomi Kario

kkario@jichi.ac.jp

1 Division of Cardiovascular Medicine, Department of Medicine, Jichi Medical University School of Medicine, Tochigi, Japan

2 Clinical Development Department, Terumo Corporation, Tokyo, Japan
In Japan, there were 43 million individuals with hypertension in 2017 [3]. Of these, only half were receiving treatment, and an even smaller proportion (just over onequarter) achieved BP control based on a target of $<140 / 90$ $\mathrm{mmHg}$ [4]. The lowering of BP targets in the latest Japanese [3] and American [5] guidelines, to $130 / 80 \mathrm{mmHg}$ for most patients with hypertension, means that the proportion of patients with adequately controlled BP is even lower [6]. Effective control of hypertension is essential to reduce cardiovascular risk $[7,8]$.

Based on the important pathophysiological role of the sympathetic nervous system in hypertension [9], catheterbased renal denervation (RDN) has been developed as a new treatment approach to reducing BP (Fig. S1) [10]. Over the last ten years, data from clinical trials of RDN have been mixed [11-13]. However, more recent studies with secondgeneration ultrasound- and radiofrequency-based RDN devices have produced promising results [14-19].

To date, there is a relative lack of data on the effects of renal denervation in Asian patients with hypertension [20]. 
This is partly due to the early termination of the SYMPLICITY-HTN-JAPAN [21] study after one of the early trials of radiofrequency RDN, the SYMPLICITY HTN-3 study, did not show a significant reduction in systolic BP (SBP) in patients with resistant hypertension treated with RDN compared with the sham control group at 6-month follow-up [11]. Nevertheless, RDN has the potential to be an useful option for Asian patients with hypertension, who have a specific disease phenotype that includes a stronger association between BP and cardiovascular disease compared with Western populations, and high salt sensitivity [22]. In addition, Asian patients appear to be more sensitive to beta-blockers [23], suggesting that RDN (as another treatment that blocks the sympathetic nervous system) may be an appropriate and effective therapy [24].

In Germany, a significant proportion of patients with elevated BP stated that they would prefer catheter-based RDN compared with ongoing antihypertensive drug therapy [25]. The current study was designed to evaluate patient preference for RDN in patients with hypertension from Japan.

\section{Methods}

\section{Study design}

An electronic survey of patients with hypertension registered with the marketing research firm Macromill Carenet was conducted in March 2020 to collect information on hypertensive outpatients in Japan (UMIN000039726). All data provided by the subjects online was anonymized and stored in a database. The study received ethical approval (approval number: CR19-R049), and all patients provided informed consent prior to completing the online survey.

\section{Study population}

Participants had regularly visited medical institutions for the treatment of hypertension with antihypertensive drug therapy. Those aged $<18$ or $>80$ years at the time of survey completion were excluded. This study included patients being treated with antihypertensive drug therapy who had home BP recordings available.

\section{Survey}

The survey collected data on participant age, sex, area of residence, comorbidities, frequency of clinic visits for hypertension management, antihypertensive drug classes prescribed, total number of antihypertensive drugs taken per day, and the most recent home and office BP values (see Supplementary Methods for full details). In addition, patients were asked about their preference for treatment with RDN based on which of the following responses they chose: "I don't want to undergo RDN"; "I'd rather not undergo RDN"; "I'd rather undergo RDN"; and "I want to undergo RDN". Patients who chose either of the last two responses were defined as having a preference for RDN.

\section{Statistical analyses}

All statistical analyses were performed using SAS 9.4 (SAS Institute, North Carolina, USA). Categorical variables are described using frequencies and percentages, while continuous variables are reported as mean values with standard deviations (SD). Categorical variables were compared using the Chi-squared test and the unpaired t-test were used to compare continuous variables between groups. The Kruskal-Wallis test was used to test for significant differences between patient preference (ordinal scale) and both BP levels and the number of antihypertensive medications. Stepwise logistic regression analysis was used to identify the predictors of patient preference for RDN. Statistical significance was defined as a two-sided $p$-value of $<0.05$.

\section{Results}

Of 4,107 patients who answered questions relating to preference for RDN, 2,392 had submitted home BP readings and were included in the current analysis. The majority of patients $(66 \%)$ were male, mean age was $59.8 \pm 11.6$ years, and mean duration of hypertension was $11.4 \pm 9.5$ years (Table 1). Baseline mean office and morning home BP values were $135.7 \pm 14.2 / 82.9 \pm 11.1 \mathrm{mmHg}$ and $134.6 \pm$ 14.3/83.1 $\pm 11.5 \mathrm{mmHg}$, respectively (Table 1 ).

\section{Patient preference for RDN}

Overall, 215 respondents $(9.0 \%)$ said that they wanted to undergo RDN and 540 (22.6\%) said that they would rather undergo RDN, meaning that a total of 755 patients (31.6\%) expressed a preference for RDN. Patient preference for RDN did not vary significantly by the number of antihypertensive agents being taken, but a higher proportion of younger versus older patients had a preference for RDN (Fig. 1).

There were significant differences in patient preference for RDN between patient subgroups based on home and office SBP values (Fig. 2). The proportion of patients expressing a preference for RDN increased as both home and office SBP increased, being highest in those with office $\mathrm{SBP} \geq 160 \mathrm{mmHg}$ or home $\mathrm{SBP} \geq 155 \mathrm{mmHg}$ (Fig. 2). In patients grade I or II hypertension [3], almost half of patients expressed a preference for RDN (Fig. 3). 
Table 1 Patient demographic and clinical characteristics at baseline

\begin{tabular}{|c|c|}
\hline Characteristic & Patients $(n=2,392)$ \\
\hline Age, years & $59.8 \pm 11.6$ \\
\hline Male, $n(\%)$ & $1,577(65.9)$ \\
\hline Body mass index, $\mathrm{kg} / \mathrm{m}^{2}$ & $25.1 \pm 4.4$ \\
\hline Duration of hypertension, years & $11.4 \pm 9.5$ \\
\hline \multicolumn{2}{|l|}{ Office blood pressure } \\
\hline $\mathrm{SBP}, \mathrm{mmHg}$ & $135.7 \pm 14.2$ \\
\hline $\mathrm{DBP}, \mathrm{mmHg}$ & $82.9 \pm 11.1$ \\
\hline $\begin{array}{l}\text { Uncontrolled SBP or DBP ( } \geq 130 \text { or } \geq 80 \\
\mathrm{mmHg}), \mathrm{n}(\%)\end{array}$ & $1,964(19.9)$ \\
\hline $\begin{array}{l}\text { Uncontrolled SBP or DBP ( } \geq 140 \text { or } \geq 90 \\
\mathrm{mmHg}), \mathrm{n}(\%)\end{array}$ & $909(57.9)$ \\
\hline \multicolumn{2}{|l|}{ Morning home blood pressure } \\
\hline $\mathrm{SBP}, \mathrm{mmHg}$ & $134.6 \pm 14.3$ \\
\hline $\mathrm{DBP}, \mathrm{mmHg}$ & $83.1 \pm 11.5$ \\
\hline $\begin{array}{l}\text { Uncontrolled SBP or DBP ( } \geq 125 \text { or } \geq 75 \\
\mathrm{mmHg}), n(\%)\end{array}$ & $2,150(89.9)$ \\
\hline $\begin{array}{l}\text { Uncontrolled SBP or DBP ( } \geq 135 \text { or } \geq 85 \\
\mathrm{mmHg}), n(\%)\end{array}$ & $1,364(57.0)$ \\
\hline \multicolumn{2}{|l|}{ Medical history, $n(\%)$} \\
\hline Diabetes mellitus & $553(23.1)$ \\
\hline Cardiovascular disease & $476(19.9)$ \\
\hline ASCVD & $442(18.5)$ \\
\hline CAD & $250(10.5)$ \\
\hline Stroke & $196(8.2)$ \\
\hline Aortic aneurysm/dissection, PAD & $123(5.1)$ \\
\hline Heart failure & $133(5.6)$ \\
\hline Chronic kidney disease & $166(6.9)$ \\
\hline \multicolumn{2}{|c|}{ Medical facility for hypertension treatment, $n(\%)$} \\
\hline Medical university hospital & $119(5.0)$ \\
\hline Hospital & $651(27.2)$ \\
\hline Clinic & $1,622(67.8)$ \\
\hline \multicolumn{2}{|l|}{ Antihypertensive therapy } \\
\hline \multicolumn{2}{|l|}{ Number of antihypertensives, $n(\%)$} \\
\hline 1 & $886(37.0)$ \\
\hline 2 & $1,261(52.7)$ \\
\hline$\geq 3$ & $245(10.2)$ \\
\hline Time on antihypertensives, years & $10.3 \pm 8.8$ \\
\hline Poor adherence ${ }^{\mathrm{a}}, n(\%)$ & $288(12.0)$ \\
\hline Side effects present ${ }^{\S}, n(\%)$ & $911(38.1)$ \\
\hline
\end{tabular}

Values are mean \pm standard deviation, or number of patients $(\%)$

apoor adherence was defined as missing at least one antihypertensive dose per week. ${ }^{\S}$ Side effects attributable to antihypertensive medication

$A S C V D$ atherosclerotic cardiovascular disease, $C A D$ coronary artery disease, $D B P$ diastolic blood pressure, $P A D$ peripheral artery disease, $S B P$ systolic blood pressure

There was also a significant relationship between adherence to antihypertensive medication and preference for RDN; patients who were less adherent to pharmacological antihypertensive therapy were significantly more likely to express a preference for RDN (Table 2).

Significant predictors of preference for RDN on logistic regression analysis were younger patient age, male sex, higher home or office SBP, poor antihypertensive drug adherence, the presence of heart failure, and presence of side effects during treatment with antihypertensive drugs (Table 3).

Specific side effects that were significantly associated with a preference for RDN on logistic regression analysis were dizziness, frequent urination, palpitation/tachycardia, dry mouth, headache, hot flashes (women) and sexual dysfunction (men) (Table S2). By far the most common source of information about hypertension and a decision to undergo RDN was the patient's physician (Fig. S2)

The expected reduction in BP after RDN was $\geq 5 \mathrm{mmHg}$ in $5.5 \%$ of patients, $\geq 10 \mathrm{mmHg}$ in $18.0 \%$ of patients, $\geq 15 \mathrm{mmHg}$ in $12.8 \%$ of patients, $\geq 20 \mathrm{mmHg}$ in $17.9 \%$ of patients, and $\geq 30 \mathrm{mmHg}$ in $10.3 \%$ of patients (the remaining patients did not want RDN) (Fig. S3).

\section{Discussion}

This is the first nationwide survey to investigate patient preference for RDN in Japanese patients with hypertension. Nearly one-third of the patients surveyed expressed a preference for RDN, and younger patients were more likely to prefer RDN than older patients. Those with more severe hypertension based on either office or home BP readings were also more likely to state a preference for RDN, with over $50 \%$ of subjects in the highest office and home BP categories preferring to undergo RDN. Both adherence to antihypertensive medication and the occurrence of drugrelated side effects increased the number of patients stating a preference for RDN. For example, those with side effects during antihypertensive therapy were more than 1.7 times more likely to prefer RDN compared to patients without side effects. In terms of comorbidities, only the presence of heart failure was a significant predictor of preference for RDN (Fig. 4).

For patients with hypertension already on drug therapy, the proportion stating that they would prefer treatment with RDN in the current study (31.6\%) was slightly higher than that in a similar study conducted in Germany (28.2\%) [25]. This may reflect the greater body of information about RDN available in the two-year period between the timing of the German study and our survey in Japan. Other potential reasons for the difference in preference rates are the younger age and higher proportion of males in our study population, because younger age and male sex were significant independent predictors of a preference for RDN on logistic regression analysis in our study. Increasing age was 


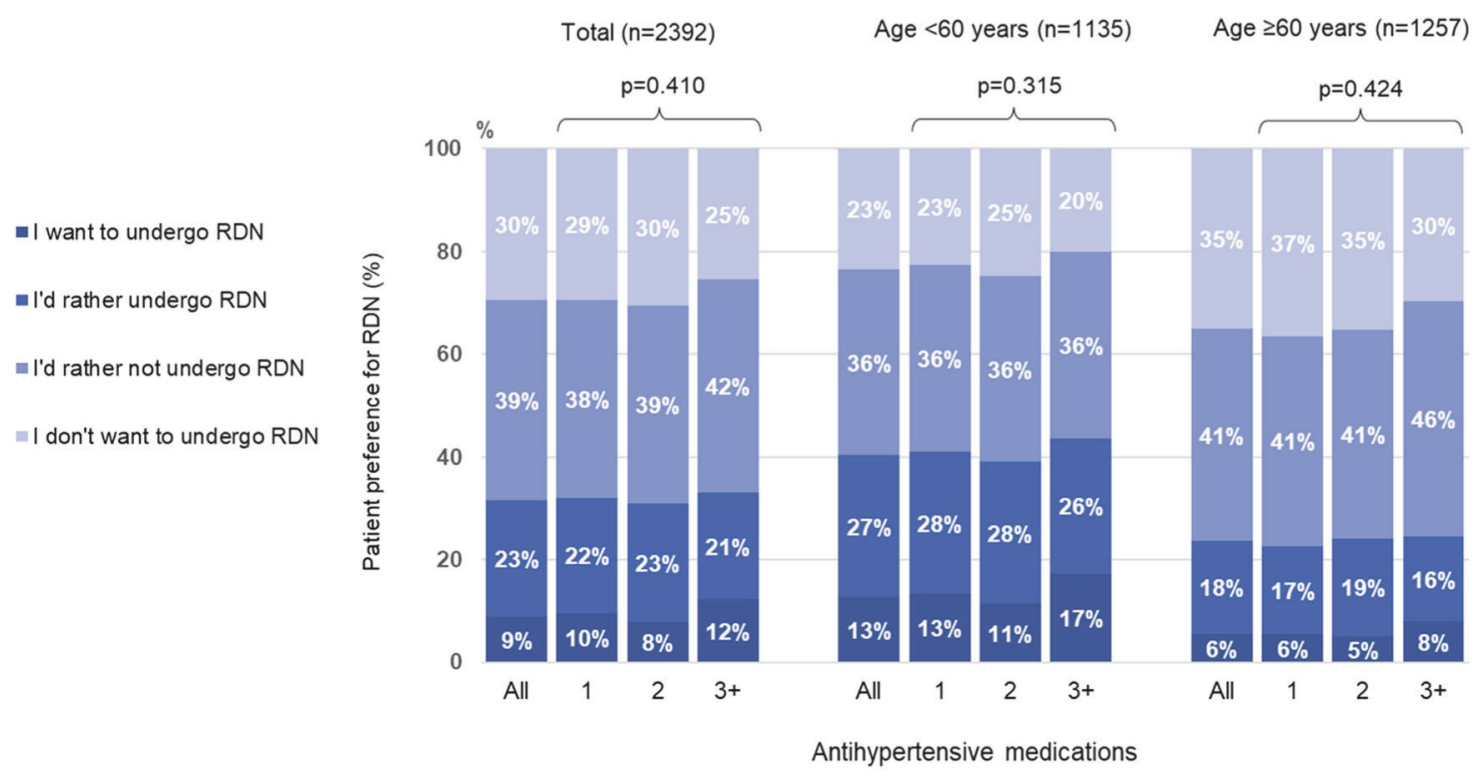

Fig. 1 Relationship between patient preference for renal denervation (RDN) and the number of antihypertensive medications in patients aged $<60$ years or $\geq 60$ years

Fig. 2 Relationship between patient preference for renal denervation (RDN) and levels of home and office systolic blood pressure (BP)

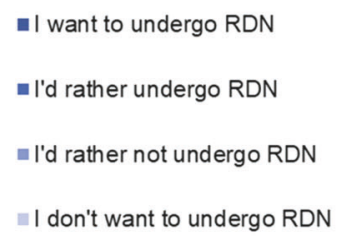

also associated with decreasing RDN preference in both the German study [25] and an analysis from Taiwan [26]. It is possible that younger patients may be more motivated than older individuals to avoid the need for long-term antihypertensive therapy and regular physician visits. Expectations about the magnitude of BP reduction that would be associated with use of RDN were equivalent between the German survey and our research conducted in Japan (Fig. S3).

Looking at baseline BP levels, increasing office SBP and home SBP were related to higher rates of patient preference for RDN (Fig. 2). The proportion of patients expressing a preference for RDN was highest in those with office SBP $\geq$
Home systolic BP ( $n=2392) \quad$ Office systolic BP $(n=2392)$

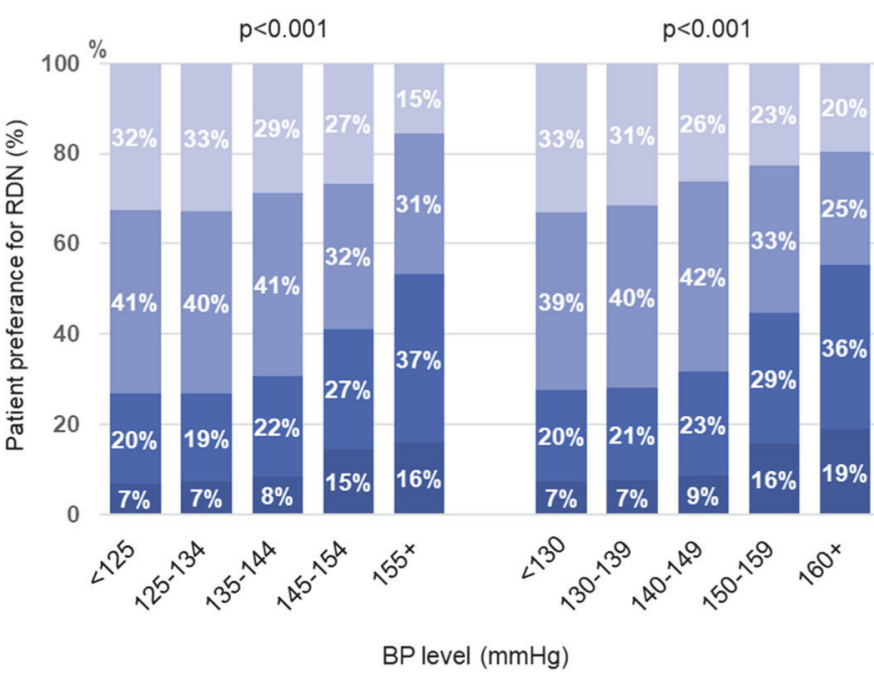

$160 \mathrm{mmHg}$ or home $\mathrm{SBP} \geq 155 \mathrm{mmHg}$. In these groups, $55 \%$ and $53 \%$ of patients, respectively, said that they wanted or preferred to undergo RDN. This is consistent with the findings of a small survey conducted in Taiwan $(n=46)$, which showed that a higher proportion of patients with resistant hypertension were more likely to choose RDN than those without resistant hypertension $(55.6 \%$ vs. $28.0 \%$, respectively) [27]. In contrast, there was no relationship between current BP level and willingness to consider treatment with RDN in an analysis of data from market research studies conducted in Europe and the United States [28].

The current study from Japan is the first to include both home and office BP in assessments of patient preference for 
Fig. 3 Relationship between patient preference for renal denervation $(\mathrm{RDN})$ and the number of antihypertensive medications in patients with grade I or grade II hypertension (as defined in the 2019 Japanese Society of Hypertension guidelines [3])
- I want to undergo RDN

- I'd rather undergo RDN

- I'd rather not undergo RDN

I I don't want to undergo RDN

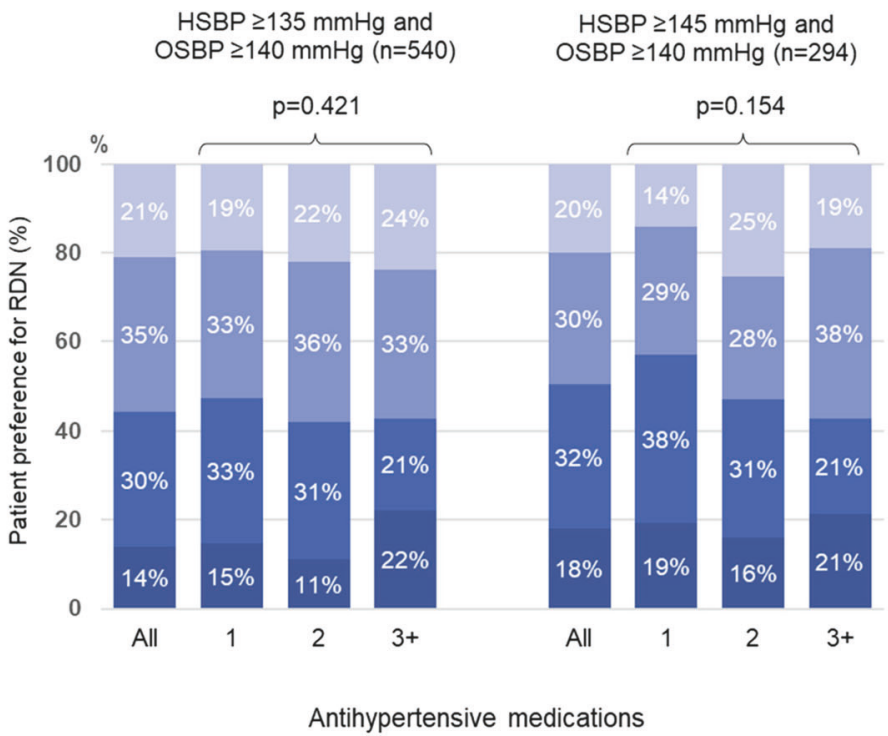

\begin{tabular}{llll}
\hline Adherence & $\begin{array}{l}\text { Number of } \\
\text { patients (\%) }\end{array}$ & $\begin{array}{l}\text { Patient preference for } \\
\text { RDN }^{\mathrm{a}}, \mathrm{n}(\%)\end{array}$ & $p$-value $^{\mathrm{b}}$ \\
\hline $\begin{array}{l}\text { Always take antihypertensives } \\
\text { Frequency of not taking }\end{array}$ & $1,582(66.1)$ & $456(28.8)$ & \\
antihypertensives: & & & \\
Once per month & $370(15.5)$ & $116(31.4)$ & \\
Once every 2 weeks & $152(6.4)$ & $63(37.5)$ & \\
Once a week & $156(6.5)$ & $23(46.9)$ & \\
Once every 2 days & $49(2.0)$ & $40(48.2)$ & \\
Don't take every day & $83(3.5)$ & &
\end{tabular}

${ }^{a}$ Patient preference for renal denervation was defined as a survey answer of "I want to undergo renal denervation" or "I would rather undergo renal denervation"

${ }^{\mathrm{b}}$ Chi-square test
RDN. Out-of-office BP measurements are increasingly being recognized as important in the diagnosis and management of hypertension [3]. Home BP is an important component of out-of-office BP measurement and has been shown to be closely associated with cardiovascular risk [29-31]. Therefore, home BP is an important measurement for all patients with hypertension.

This survey showed that heart failure was the only comorbidity that was significantly associated with a preference for RDN. No specific information on the presence of heart failure was reported in the German survey [25]. However, combined data from Europe and the US showed that a significantly higher proportion of patients with comorbidities were willing to consider RDN rather than antihypertensive drug therapy [28]. The observed significant relationship between the presence of heart failure and preference for RDN in patients with hypertension in our survey likely reflects the symptomatic nature of heart failure and the desire for symptom resolution, and perhaps also the potentially positive effects of RDN in patients with heart failure [32-37]. In addition, patients with comorbidities may be more aware of the negative effects of hypertension on cardiovascular risk and renal disease, making them more likely to be motivated to reduce their BP.

We found a link between poor adherence to antihypertensive medication and patient preference for RDN. The proportion of patients in our survey who said that they "always adhere to antihypertensives" was $66 \%$, compared with approximately $80 \%$ in other surveys [25, 28]. It does seem logical that patients who struggle to adhere to antihypertensive medication regimens would prefer a treatment that does not appear to require regular drug taking. However, antihypertensive drug usage might still continue after $\mathrm{RDN}$, and inconsistent adherence to prescribed drugs after the procedure has been reported, with frequent nonadherence to antihypertensive medication [18]. Nevertheless, should accumulating clinical trial data continue to show that RDN has consistent and durable effects on BP in patients with hypertension, it would have the advantage of not being dependent on daily actions by the patient. 
Table 3 Determinants of patient preference for renal denervation

\begin{tabular}{|c|c|c|c|c|c|c|}
\hline \multirow[t]{2}{*}{ Variable } & \multirow[t]{2}{*}{$N$} & \multirow{2}{*}{$\begin{array}{l}\text { Patient preference }{ }^{\mathrm{a}}, \\
n(\%)\end{array}$} & \multicolumn{2}{|l|}{ Univariate analysis } & \multicolumn{2}{|c|}{ Logistic regression analysis } \\
\hline & & & $\begin{array}{l}\text { Crude OR } \\
(95 \% \mathrm{CI})\end{array}$ & $\begin{array}{l}\text { Crude } \\
p \text {-value }\end{array}$ & $\begin{array}{l}\text { Adjusted OR } \\
(95 \% \mathrm{CI})\end{array}$ & $\begin{array}{l}\text { Adjusted } \\
p \text {-value }\end{array}$ \\
\hline \multicolumn{7}{|l|}{ Age, years } \\
\hline$\leq 49$ & 552 & $250(45.3)$ & $3.23(2.51-4.16)$ & $<0.001$ & $2.99(2.29-3.09)$ & $<0.001$ \\
\hline $50-59$ & 583 & $207(35.5)$ & $2.15(1.66-2.77)$ & $<0.001$ & $2.24(1.72-2.92)$ & $<0.001$ \\
\hline $60-69$ & 605 & $165(27.3)$ & $1.46(1.13-1.90)$ & 0.004 & $1.51(1.15-1.98)$ & 0.003 \\
\hline$\geq 70$ & 652 & $133(20.4)$ & reference & - & reference & - \\
\hline \multicolumn{7}{|l|}{ Sex } \\
\hline Male & 1,577 & $553(35.1)$ & $1.64(1.36-1.98)$ & $<0.001$ & $1.71(1.40-2.08)$ & $<0.001$ \\
\hline Female & 815 & $202(24.8)$ & reference & - & reference & - \\
\hline \multicolumn{7}{|c|}{ Office SBP, mmHg } \\
\hline$\geq 160$ & 159 & $88(55.4)$ & $3.26(2.28-4.64)$ & $<0.001$ & $1.71(1.16-2.53)$ & 0.007 \\
\hline $150-159$ & 173 & $77(44.5)$ & $2.11(1.49-2.97)$ & $<0.001$ & $1.63(1.15-2.29)$ & 0.006 \\
\hline $140-149$ & 430 & $136(31.6)$ & $1.21(0.93-1.58)$ & 0.147 & n.s. & - \\
\hline $130-139$ & 941 & $264(28.2)$ & $1.02(0.82-1.28)$ & 0.831 & n.s. & - \\
\hline$\leq 129$ & 689 & $190(27.6)$ & reference & - & reference & - \\
\hline \multicolumn{7}{|c|}{ Home SBP, mmHg } \\
\hline$\geq 155$ & 201 & $107(53.2)$ & $3.11(2.22-4.36)$ & $<0.001$ & $1.65(1.16-2.35)$ & 0.006 \\
\hline $145-154$ & 255 & $105(41.2)$ & $1.91(1.40-2.62)$ & $<0.001$ & $1.42(1.06-1.89)$ & 0.018 \\
\hline $135-144$ & 622 & $191(30.7)$ & $1.21(0.94-1.57)$ & 0.144 & n.s. & - \\
\hline $125-134$ & 784 & $210(26.8)$ & $1.02(0.82-1.28)$ & 0.831 & n.s. & - \\
\hline$\leq 124$ & 530 & $142(26.8)$ & reference & - & reference & - \\
\hline \multicolumn{7}{|c|}{ Comorbidity } \\
\hline \multicolumn{7}{|c|}{ Diabetes mellitus } \\
\hline Present & 553 & $198(35.8)$ & $1.28(1.05-1.57)$ & 0.014 & n.s. & - \\
\hline Absent & 1,839 & $557(30.3)$ & reference & - & reference & - \\
\hline \multicolumn{7}{|l|}{ CAD } \\
\hline Present & 250 & 94 (37.6) & $1.35(1.03-1.77)$ & 0.030 & n.s. & - \\
\hline Absent & 2,142 & $661(30.9)$ & reference & - & reference & - \\
\hline \multicolumn{7}{|l|}{ Stroke } \\
\hline Present & 196 & $81(41.3)$ & $1.59(1.18-2.14)$ & 0.002 & n.s. & - \\
\hline Absent & 2,196 & $674(30.7)$ & reference & - & reference & - \\
\hline \multicolumn{7}{|c|}{ Aortic aneurysm/dissection, PAD } \\
\hline Present & 123 & $51(41.5)$ & $1.57(1.09-2.28)$ & 0.015 & n.s. & - \\
\hline Absent & 2,269 & $704(31.0)$ & reference & - & reference & - \\
\hline \multicolumn{7}{|c|}{ Heart failure } \\
\hline Present & 133 & $63(47.4)$ & $2.04(1.43-2.90)$ & $<0.001$ & $1.51(1.02-2.22)$ & 0.039 \\
\hline Absent & 2,259 & $692(30.6)$ & reference & - & reference & - \\
\hline \multicolumn{7}{|c|}{ Chronic kidney disease } \\
\hline Present & 166 & 64 (38.6) & $1.39(1.01-1.93)$ & 0.045 & n.s. & - \\
\hline Absent & 2,226 & $691(31.0)$ & reference & - & reference & - \\
\hline \multicolumn{7}{|c|}{ Adherence ${ }^{\mathbf{b}}$} \\
\hline Poor & 288 & $126(43.8)$ & $1.82(1.42-2.34)$ & $<0.001$ & $1.39(1.06-1.82)$ & 0.017 \\
\hline Good & 2,104 & $629(29.9)$ & reference & - & reference & - \\
\hline \multicolumn{7}{|c|}{ Side effects ${ }^{\S}$} \\
\hline Present & 911 & $375(41.2)$ & $2.03(1.70-2.42)$ & $<0.001$ & $1.74(1.44-2.09)$ & $<0.001$ \\
\hline Absent & 1,481 & $390(25.7)$ & reference & - & reference & - \\
\hline
\end{tabular}

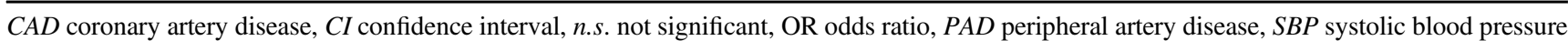
${ }^{a}$ Patient preference for renal denervation was defined as a survey answer of "I want to undergo renal denervation" or "I would rather undergo renal denervation"

${ }^{b}$ Poor adherence was defined as missing at least one antihypertensive dose per week. ${ }^{\S}$ Side effects attributable to antihypertensive medication

Another potential limitation of antihypertensive drug therapy that is overcome by the use of RDN is drug-induced adverse events. In the current survey, $38 \%$ of patients reported side effects related to their antihypertensive medications, and patients with side effects were 1.7 times more likely to express a preference for RDN than those without 

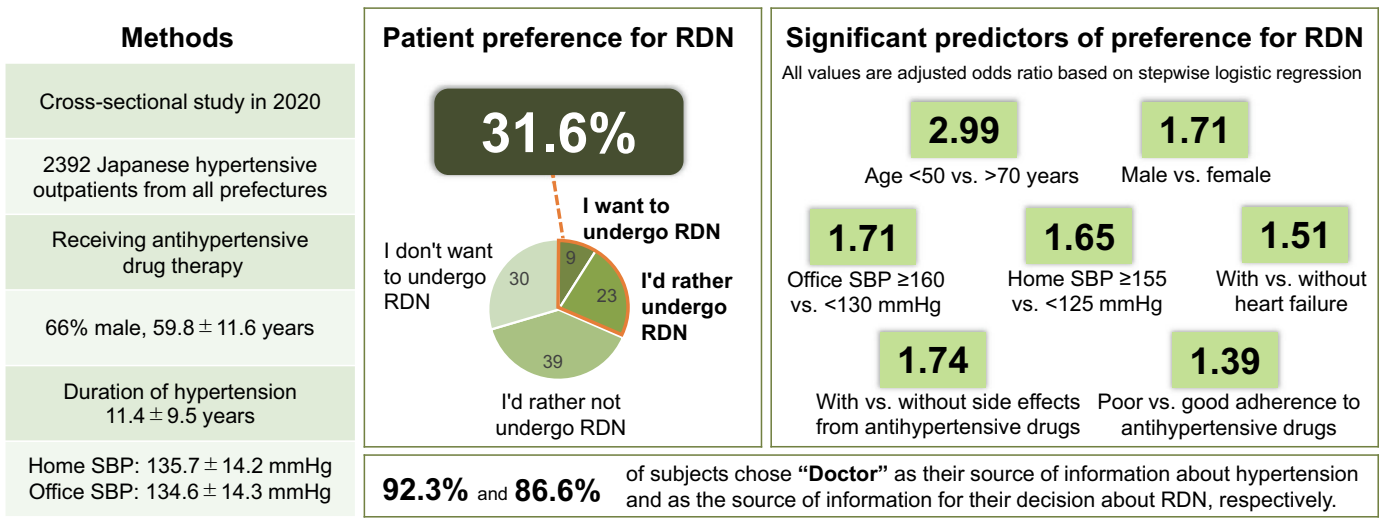

Fig. 4 Graphical Abstract: A relevant proportion of patients with hypertension expressed a preference for renal denervation. This should be taken into account when making shared decisions about antihypertensive drug therapy

side effects. These findings are consistent with several other surveys that have reported higher rates of preference for RDN in patients with antihypertensive-related adverse effects [25-28].

The fact that $87 \%$ of patients in our study stated that their doctor was the source of information they used to make a decision about RDN (Fig. S2) highlights the important role of physicians in educating and informing patients about their treatment options, as well as hypertension itself. The key role of physicians has also been highlighted in other studies of patient preference for RDN [25, 28]. Therefore, there is a need for continued research in this area to allow physicians to provide their patients with robust data on which to make informed decisions about whether to undergo RDN for the treatment of hypertension.

The current body of evidence for the efficacy and safety of RDN from sham-controlled clinical trials means that a recent European Society of Hypertension position paper has described RDN as an appropriate, evidence-based option for the treatment of hypertension [38]. In addition, guidance from Asian experts [39] and the Italian Society of Arterial Hypertension [40] notes that RDN has a role in the management of difficult-to-treat, resistant or uncontrolled hypertension, and that RDN could be considered as an earlier line of therapy rather than just a "last resort" option [39]. These recommendations provide good evidence-based guidance, but any decision about treatment options should be a shared process between the patient and their physician that also takes patient preference into account.

\section{Strengths and limitations}

The key strength of this study is the large sample size that includes patients from all prefectures across Japan. However, the results have limited external validity because they are only applicable to the setting in which they were obtained (i.e. Japanese patients with hypertension). Furthermore, this was a self-reported internet survey, meaning that source verification was not performed and the sample may be non-representative; for example, there may have been fewer responses from patients with hypertension who were less familiar with the internet and older adults. Another important point to note is that the data in this study are relevant to the time the survey was conducted, and do not reflect any potential effects of subsequent publications showing the efficacy and tolerability of RDN, such as the RADIANCE-HTN TRIO study [14], on patient preference and physician recommendations. Finally, adherence was self reported and was not verified using a validated questionnaire (e.g. Morinsky Medication Adherence [MMAS8]) or any objective measures.

\section{Conclusions}

A relevant proportion of Japanese patients with hypertension expressed a preference for RDN, especially males, younger patients, those experiencing drug-related side effects or non-adherence, and in patients with higher BP levels or comorbid heart failure. Patient preference should be taken into account when making shared decisions about antihypertensive therapy, alongside BP values, circadian patterns of $\mathrm{BP}$, the overall cardiovascular risk profile, and tolerability and adherence to drug treatment.

Acknowledgements Medical writing support was provided by Nicola Ryan, independent medical writer, funded by Terumo Corporation.

Author contributions K. Kario, H. Kagitani, S. Hiyashi, S. Hanamura and K. Ozawa were involved in study design and data interpretation. H. Kagitani and H. Kanegae were responsible for the data analysis. All authors critically revised the report, commented on drafts of the manuscript, and approved the final report. 


\section{Compliance with ethical standards}

Conflict of interest K. Kario is contracted as an external medical adviser to Terumo Corporation. K. Kario has received speaker fees and works as a consultant to JIMRO Co.; research grant from Otsuka Medical Devices, Co., all outside the submitted work. H. Kagitani, S. Hayashi, S. Hanamura, and K. Ozawa are full-time employees of Terumo Corporation. H. Kanegae has no conflicts of interest to declare.

Publisher's note Springer Nature remains neutral with regard to jurisdictional claims in published maps and institutional affiliations.

Open Access This article is licensed under a Creative Commons Attribution 4.0 International License, which permits use, sharing, adaptation, distribution and reproduction in any medium or format, as long as you give appropriate credit to the original author(s) and the source, provide a link to the Creative Commons license, and indicate if changes were made. The images or other third party material in this article are included in the article's Creative Commons license, unless indicated otherwise in a credit line to the material. If material is not included in the article's Creative Commons license and your intended use is not permitted by statutory regulation or exceeds the permitted use, you will need to obtain permission directly from the copyright holder. To view a copy of this license, visit http://creativecommons. org/licenses/by/4.0/.

\section{References}

1. World Health Organization. Hypertension fact sheet. Available at: https://www.who.int/news-room/fact-sheets/detail/hypertension. Accessed 10 Aug 2021).

2. Chobanian AV, Shattuck Lecture. The hypertension paradox-more uncontrolled disease despite improved therapy. N. Engl J Med. 2009;361:878-87.

3. Umemura S, Arima H, Arima S, Asayama K, Dohi Y, Hirooka Y, et al. The Japanese Society of Hypertension Guidelines for the Management of Hypertension (JSH 2019). Hypertens Res. 2019;42:1235-481.

4. Hirawa N, Umemura S, Ito S. Viewpoint on Guidelines for Treatment of Hypertension in Japan. Circulation Res. 2019;124:981-3.

5. Whelton PK, Carey RM, Aronow WS, Casey DE Jr., Collins KJ, Dennison Himmelfarb C, et al. 2017 ACC/AHA/AAPA/ABC/ ACPM/AGS/APhA/ASH/ASPC/NMA/PCNA Guideline for the prevention, detection, evaluation, and management of high blood pressure in adults: executive summary: a report of the American College of Cardiology/American Heart Association Task Force on Clinical Practice Guidelines. Hypertension. 2018;71:1269-324.

6. Kario K. Global impact of 2017 American Heart Association/ American college of cardiology hypertension guidelines. Circulation. 2018;137:543-5.

7. Lewington S, Clarke R, Qizilbash N, Peto R, Collins R. Agespecific relevance of usual blood pressure to vascular mortality: a meta-analysis of individual data for one million adults in 61 prospective studies. Lancet. 2002;360:1903-13.

8. Bundy JD, Li C, Stuchlik P, Bu X, Kelly TN, Mills KT, et al. Systolic blood pressure reduction and risk of cardiovascular disease and mortality: a systematic review and network metaanalysis. JAMA Cardiol. 2017;2:775-81.

9. Esler M, Lambert E, Schlaich M. Point: chronic activation of the sympathetic nervous system is the dominant contributor to systemic hypertension. J Appl Physiol (1985). 2010;109:1996-8. discussion 2016
10. Katsurada K, Ogoyama Y, Imai Y, Patel KP, Kario K. New horizons in the treatment of hypertension: renal denervation based on experimental rationale. Hypertens Res. 2021 (e-pub ahead of print 2021/09/13, https://doi.org/10.1038/s41440-021-00746-7).

11. Bhatt DL, Kandzari DE, O'Neill WW, D'Agostino R, Flack JM, Katzen BT, et al. A controlled trial of renal denervation for resistant hypertension. N. Engl J Med. 2014;370:1393-401.

12. Esler MD, Krum H, Sobotka PA, Schlaich MP, Schmieder RE, Böhm M. Renal sympathetic denervation in patients with treatment-resistant hypertension (The Symplicity HTN-2 Trial): a randomised controlled trial. Lancet. 2010;376:1903-9.

13. Krum H, Schlaich M, Whitbourn R, Sobotka PA, Sadowski J, Bartus $\mathrm{K}$, et al. Catheter-based renal sympathetic denervation for resistant hypertension: a multicentre safety and proof-of-principle cohort study. Lancet. 2009;373:1275-81.

14. Azizi M, Sanghvi K, Saxena M, Gosse P, Reilly JP, Levy T, et al. Ultrasound renal denervation for hypertension resistant to a triple medication pill (RADIANCE-HTN TRIO): a randomised, multicentre, single-blind, sham-controlled trial. Lancet. 2021;397:2476-86.

15. Azizi M, Schmieder RE, Mahfoud F, Weber MA, Daemen J, Davies J, et al. Endovascular ultrasound renal denervation to treat hypertension (RADIANCE-HTN SOLO): a multicentre, international, single-blind, randomised, sham-controlled trial. Lancet. 2018;391:2335-45.

16. Azizi M, Schmieder RE, Mahfoud F, Weber MA, Daemen J, Lobo $\mathrm{MD}$, et al. Six-month results of treatment-blinded medication titration for hypertension control after randomization to endovascular ultrasound renal denervation or a sham procedure in the RADIANCE-HTN SOLO trial. Circulation. 2019;139:2542-53.

17. Böhm M, Kario K, Kandzari DE, Mahfoud F, Weber MA, Schmieder RE, et al. Efficacy of catheter-based renal denervation in the absence of antihypertensive medications (SPYRAL HTNOFF MED Pivotal): a multicentre, randomised, sham-controlled trial. Lancet. 2020;395:1444-51.

18. Kandzari DE, Böhm M, Mahfoud F, Townsend RR, Weber MA, Pocock S, et al. Effect of renal denervation on blood pressure in the presence of antihypertensive drugs: 6-month efficacy and safety results from the SPYRAL HTN-ON MED proof-of-concept randomised trial. Lancet. 2018;391:2346-55.

19. Townsend RR, Mahfoud F, Kandzari DE, Kario K, Pocock S, Weber MA, et al. Catheter-based renal denervation in patients with uncontrolled hypertension in the absence of antihypertensive medications (SPYRAL HTN-OFF MED): a randomised, shamcontrolled, proof-of-concept trial. Lancet. 2017;390:2160-70.

20. Kim BK, Kim HS, Park SJ, Park CG, Seung KB, Gwon HC, et al. Long-term outcomes after renal denervation in an Asian population: results from the Global SYMPLICITY Registry in South Korea (GSR Korea). Hypertens Res. 2021;44:1099-104.

21. Kario K, Ogawa H, Okumura K, Okura T, Saito S, Ueno T, et al. SYMPLICITY HTN-Japan - first randomized controlled trial of catheter-based renal denervation in Asian patients. Circ J. 2015;79:1222-9.

22. Kario K, Chen CH, Park S, Park CG, Hoshide S, Cheng HM, et al. Consensus document on improving hypertension management in Asian patients, taking into account Asian characteristics. Hypertension. 2018;71:375-82.

23. Zhou HH, Koshakji RP, Silberstein DJ, Wilkinson GR, Wood AJ. Racial differences in drug response. Altered sensitivity to and clearance of propranolol in men of Chinese descent as compared with American whites. N. Engl J Med. 1989;320:565-70.

24. Okamura K, Shirai K, Okuda T, Urata H. The prevalence of Japanese outpatients with hypertension who meet the definition of treatment resistant hypertension and are eligible for enrolment in clinical trials of endovascular ultrasound renal denervation. Intern Med. 2018;57:1-12. 
25. Schmieder RE, Högerl K, Jung S, Bramlage P, Veelken R, Ott C. Patient preference for therapies in hypertension: a cross-sectional survey of German patients. Clin Res Cardiol. 2019;108:1331-42.

26. Lin S-I, Li SH-W, Lan W-R, Liao F-C, Tsai CT, Lee Y-H. Understanding the patient preference for catheter-based hypertension therapy: a pilot study for physician awareness of patients' behaviour in Taiwan. J Am Coll Cardiol. 2020;75:3586.

27. Lin S-I, Li SH-W, Lan W-R, Liao F-C, Tsai CT, Lee Y-H. Subtypes of patient preference for catheter-based hypertension hterapy: a piloto study based on Taiwan consensus on renal denervation (RDNI2). J Am Coll Cardiol. 2020;75:3507.

28. Schmieder RE, Kandzari DE, Wang TD, Lee YH, Lazarus G, Pathak A. Differences in patient and physician perspectives on pharmaceutical therapy and renal denervation for the management of hypertension. J Hypertens. 2021;39:162-8.

29. Hoshide S, Yano Y, Haimoto H, Yamagiwa K, Uchiba K, Nagasaka $S$, et al. Morning and evening home blood pressure and risks of incident stroke and coronary artery disease in the Japanese general practice population: the Japan morning surge-home blood pressure study. Hypertension. 2016;68:54-61.

30. Kario K, Saito I, Kushiro T, Teramukai S, Ishikawa Y, Mori Y, et al. Home blood pressure and cardiovascular outcomes in patients during antihypertensive therapy: primary results of HONEST, a large-scale prospective, real-world observational study. Hypertension. 2014;64:989-96.

31. Watabe D, Asayama K, Hanazawa T, Hosaka M, Satoh M, Yasui $\mathrm{D}$, et al. Predictive power of home blood pressure indices at baseline and during follow-up in hypertensive patients: HOMEDBP study. Hypertens Res. 2018;41:622-8.

32. Chen W, Ling Z, Xu Y, Liu Z, Su L, Du H, et al. Preliminary effects of renal denervation with saline irrigated catheter on cardiac systolic function in patients with heart failure: a prospective, randomized, controlled, pilot study. Catheter Cardiovasc Inter. 2017;89:E153-e161.

33. Dai Q, Lu J, Wang B, Ma G. Effect of percutaneous renal sympathetic nerve radiofrequency ablation in patients with severe heart failure. Int J Clin Exp Med. 2015;8:9779-85.

34. Davies JE, Manisty CH, Petraco R, Barron AJ, Unsworth B, Mayet J, et al. First-in-man safety evaluation of renal denervation for chronic systolic heart failure: primary outcome from REACHPilot study. Int J Cardiol. 2013;162:189-92.

35. Fukuta H, Goto T, Wakami K, Ohte N. Effects of catheter-based renal denervation on heart failure with reduced ejection fraction: a systematic review and meta-analysis. Heart Fail Rev. 2017;22:657-64.

36. Gao JQ, Xie Y, Yang W, Zheng JP, Liu ZJ. Effects of percutaneous renal sympathetic denervation on cardiac function and exercise tolerance in patients with chronic heart failure. Rev Port Cardiol. 2017;36:45-51.

37. Kresoja KP, Rommel KP, Fengler K, von Roeder M, Besler C, Lücke $\mathrm{C}$, et al. Renal sympathetic denervation in patients with heart failure with preserved ejection fraction. Circ Heart Fail. 2021;14:e07421.

38. Schmieder RE, Mahfoud F, Mancia G, Azizi M, Böhm M, Dimitriadis K, et al. European Society of Hypertension position paper on renal denervation 2021. J Hypertens. 2021;39: $1733-41$

39. Kario K, Kim BK, Aoki J, Wong AY, Lee YH, Wongpraparut N, et al. Renal denervation in Asia: consensus statement of the asia renal denervation consortium. Hypertension 2020;75:590-602.

40. Bruno RM, Taddei S, Borghi C, Colivicchi F, Desideri G, Grassi G, et al. Italian Society of Arterial Hypertension (SIIA) position paper on the role of renal denervation in the management of the difficult-to-treat hypertensive patient. High Blood Press Cardiovasc Prev. 2020;27:109-17. 